business administration of these studies, their financial management and adherence to a well formulated and construed scientific protocol so as to gain an outcome of high quality. And this has to happen without loss of trust and without a stifling bureaucracy.

The mechanisms which must be added to the normal practice of good clinical trials are monitoring by the MRC, independent scientific advice, a committee with the remit of trial management without loss of "blindness" to the data (the trial steering committee) and another to monitor progress of the trial in relation to ethical probity, adverse events and novel information about matters relevant to the trial. This is done by an independent but "unblinded" group, the data and monitoring and ethics committee. This group is not to substitute for the local research ethics committee, whose review is an essential preliminary to the study. Also the roles and remits of principal investigators, investigators and host institutions are set out clearly. So, the added arrangements which impinge on ethics are the presence of independent scientific advisors, of a committee which reviews data as it accrues without "blindness" but in confidence, and the defined responsibilities of the heads of host institutions to be accountable in part for what goes on with the trials in those institutions.

What of the ethical aspects of these guidelines? These are set out, in part 2, along lines which mirror almost exactly the current Helsinki Declaration revision; the declaration does, of course, deal with broad principles. The actual places where most difficulties arise are not in relation to the principles but in their application. For example the guidelines barely discuss, or omit entirely, reference to many well-known "minefields": the problems of justice and "equipoise"; those of indemnity (factors which jeopardise it, how non-negligent injury is compensable in its various sectors); those of product importation and registration (as set out in recent revisions of MAL 30 and European directives); those of volunteer groups who are specially vulnerable; those of consent $\mathrm{v}$ assent and of the ascertainment, elicitation and validation of informed consent; those of the implications for volunteers of divulgence to themselves of personally sensitive information (for example test results), and those of payments made to participants. There are also the important issues of concurrent therapy which is not part of the trial comparison, and of the definition (given in the guidelines) of what is a "serious adverse event"; this seems to be largely confined to injury or illness caused as opposed to other potential harms. The issues of partially informed consent are raised and helpfully presented, as are those of data-handling and of confidentiality.

It is welcome to see a clear statement, in line with the Helsinki Declaration, that the clinical participants' safety and benefit are paramount over social and scientific interests, and that part of ensuring this relies on there being adequately qualified clinical staff who are to be responsible for patient care. It is less clear what is implied by the statements that there are pieces of information to which a participant "should have access"; these are about compensation, treatment after harm, and progress with, and the eventual outcome of, the trial. This is a special concern since the MRC like the National Health Service and other public bodies is unable to insure and so cannot offer advance indemnity for non-negligent injury to participants in its studies.

The guidelines end with appendices which include some helpful checklists for applicants for MRC funding and for those setting up the committees required for clinical trials.

The council clearly aims to draft guidelines which will be useful not only to its own research groups but to all institutions conducting clinical trials outside the pharmaceutical industry. What has been set down is an excellent template for such work in general, but it cannot be held to be mandatory in every such situation, nor can it absolve anyone from careful ethical review.

There will be room for much detailed comment on clinical trial proposals by local or national ethics committees in view of the difficulties of applying the ethical principles listed here. Perhaps a further appendix outlining some of these questions might be helpful; they are of frequent importance in the design and execution of clinical trials.

DUNCAN VERE

Emeritus Professor of Therapeutics, University of London
Assisted Reproductive Technologies: Analysis and Recommendations for Public Policy

The New York State Task Force on

Life and the Law, New York, 1998, $474+\mathrm{ix}$-xxxiv pages, $\$ 12.00$.

Assisted Reproductive Technologies (ARTs) include in vitro fertilisation (IVF) and artificial insemination (AI). They raise similar moral, ethical and legal issues throughout the world. What procedures should be permitted - and who should have access to them?

Should ART be limited to married couples or should single and gay people be admitted to IVF programmes? Should they be limited to using their own gametes or should donor gametes and embryos be allowed? Should embryos be frozen if that increases the likelihood of a successful pregnancy? Should fetal reduction (the killing of embryos in utero) be permitted in multiple pregnancies to increase the chance of survival for some of the embryos? Should children born from donated gametes or embryos in ART be entitled to know their biological parents? Should research be permitted on embryos - and in what circumstances? All of these questions - and many others in a similar vein - are extensively discussed in this report.

The New York State Task Force on Life and the Law was created in 1985 to recommend policy for New York state in the form of legislation, regulation, public education or other measures. Medical advances on which it has advised to date include the determination of death, the withholding and withdrawal of life-sustaining treatment, organ transplantation and ARTs. Six of its recommendations for legislation or regulation have been enacted in New York state. For this reason alone, this report is likely to be influential, at least in the United States.

For readers in the United States or elsewhere, whether medical or other experts or general readers, the report will be informative and stimulating. It is written in a readily accessible style with summaries of submissions made by many and diverse people during the task force's consultation process infertile couples, participants in ART programmes, support groups of various types, ART practitioners, representatives of religious groups and the general public. The range of views that 
has informed the report is one of its greatest strengths.

The focus of the report is on American law and practice but there are some references to inquiries into ART in other countries, (these are fewer than one might expect. In the 11-page index, the Warnock Committee is not listed - though the Human Fertilisation and Embryology Authority is mentioned once; and the [Victorian] Waller Committee which has published a number of influential reports in Australia on ethical and legal aspects of ART which have been implemented in legislation, is listed only in relation to its advice on the disposition of the Rios frozen embryos).

The report is very well researched and, in the American style, there are copious footnotes (though no bibliography). There is an extensive executive summary (pages $x i-x x x i i)$ and a summary of legislative and regulatory recommendations (pages 445-451; there are two minority reports, by four members and one member respectively: pages 453-462)

Recommendations are made on issues that have proved especially contentious in other jurisdictions. These are illustrated by the recommendations on "gestational surrogacy arrangements" (this means that the surrogate's own eggs are not used - the gametes come from the intended parents). If the genetic mother and the surrogate mother agree after the child's birth that the latter should be the child's legal mother, then she should be able to obtain a judicial declaration for a formal adoption. If the two women cannot agree, each should be entitled to apply for custody and other rights with respect to the child; the court could then resolve the dispute and appoint one mother, based on the best interests of the child. However, the other mother's status as a biological mother should not be terminated "unless circumstances ordinarily justifying the involuntary termination of parental status are shown to exist" (page 446). If the intended parents change their minds and will not accept the child after its birth, the surrogate mother should have the right to obtain a declaration of the legal obligations of both the genetic mother and father (page 446).

There are also some interesting recommendations concerning the theft of gametes and embryos (which has apparently occurred in California). The report states that it should be a criminal offence knowingly to transfer a person's gametes, or embryos into anyone except that person or that person's spouse without the written consent of the donor and the recipient. Similarly gametes should not be removed from a deceased or incompetent person unless he or she has consented in writing to that in the specific circumstances while able to do so.

In short, this is a book that will stimulate and inform discussion by providing a range of views on many topical issues arising from ART. Although the law in countries outside the United States is barely mentioned, this should not deter readers in other countries. Ethical debate is independent of geographical boundaries!

LOANE SKENE Associate Professor and Reader, Director of Studies, Health and Medical Law, Law School, University of Melbourne,

Australia

\section{Making Sense of MacIntyre}

\section{Michael Fuller, Aldershot, Ashgate, 1998, 143 pages, $£ 35$.}

This short book makes a promise, which it largely fulfils. The author offers to guide us through the intricacies of Alasdair MacIntyre's trilogy, After Virtue, Whose fustice, Which Rationality? and Three Rival Versions of Moral Enquiry, in order to help us grasp the basic thesis of these works. MacIntyre claims that the whole edifice of modern moral and political philosophy rests on crumbling foundations, and as a consequence that our individual and collective lives in modern liberal societies are in a dangerous moral muddle, from which we urgently need to be rescued by the restoration of a unifying moral vision. Fuller describes his project of "making sense of MacIntyre" as "a slippery but rewarding task" (page viii). Anyone who has tried to read all three of MacIntyre's long and complex volumes must surely agree with him. They are so densely packed with scholarly reference and detailed argumentation in tortuous sentences, that they remind this reviewer of one critic's description of Wagnerian opera: "glorious moments but dreadful half hours". Fuller's lucid prose and carefully structured analysis are a welcome relief from the much more discursive style of MacIntyre. Yet, although he surveys a wide range of interrelated issues in a book of only four chapters,
Fuller does not oversimplify the differ cult theoretical issues. This is certainfy not a "dumbing down" of philosoph but it is an attempt to lead the readef (willing to persevere with some quice abstract material) through the diffe 은 ent phases of MacIntyre's critique and to appreciate why the issues he raise are of such fundamental importange to us all.

Fuller's exposition is greatly en $\vec{P}$ hanced by his decision to use anothen contemporary philosopher, Richars Rorty, as a foil to MacIntyre. Rorty account of the "liberal ironist" another attempt to deal with thif uncertainty and confusion of moderm moral, social and political life, but orie which holds onto (albeit ironically) the liberal vision which MacIntyre dis cards. Fuller's use of Rorty in this way is an inspired move, because his view is a genuine alternative to MacIntyre $\frac{5}{3}$ and his analysis of the central issues of the epistemology of morals is of equad scholarly weight. Fuller thus sets up debate between the two approaches allowing the reader as spectator of the bout to decide on the victor. Fulle himself appears to lean towards Rort鹿 though not in any conclusive wao Nevertheless, some of his conclusion about MacIntyre are fairly damnin For example, he concludes that MacIntyre's account of a return to tradition appears to be, once all th ambiguity and qualification is cleared away, simply a call to return something like the theocentric societief of mediaeval Thomism. Fuller remarks "This is about as realistic as expecting liberal democracies to embrace Islam民 Fundamentalism as a core ideology (page 140), and so his preference migin be for Rorty's passionate liberalism despite its lack of secure intellectua foundation. However, here as elsewhere in the volume, Fuller is very quick tof show why the MacIntyre style of analyo sis must cast doubt on any liberat dream of a world community. Thus the author, despite occasional lapses, stay largely to his task of helping the reade? to make sense of MacIntyre, leaving any final evaluation of the MacIntyre thesis to the reader.

Why should people interested io medical ethics or bioethics bother wit this book, or indeed with the origin writings on which it depends? Since neither Fuller nor MacIntyre (in the writings being surveyed) raise specifio topics of relevance to medicine and health care, what is the point entering this somewhat rarefie? philosophical terrain? An answer to these questions can be offered at two 